\title{
Fantasmas do futuro: a clínica do virtual
}

\section{Phantoms of the future: the clinic of the virtual}

\section{J uliane Tagliari Farina*}

Doutoranda do Programa de Pós-Graduação em Psicologia Social e Institucional da Universidade Federal do Rio Grande do Sul - UFRGS, Porto Alegre, RS, Brasil

\section{Tânia Mara Galli Fonseca**}

Professora dos Programas de Pós-Graduação em Psicologia Social e Institucional e de Informática Educativa da Universidade Federal do Rio Grande do Sul - UFRGS, Porto Alegre, RS, Brasil

\begin{abstract}
RESUMO
O presente artigo toma conceitos desenvolvidos por Gilles Deleuze na obra Diferença e Repetição como ferramentas para a produção de uma perspectiva crítica das noções de subjetividade e tempo no campo clínico da Psicologia. Tal perspectiva convoca um exercício cartográfico dos efeitos desses conceitos no fazer e no pensar de uma prática clínica diferenciada, a partir de um pensamento descolado das categorias representacionais, e reencontrado numa dimensão imanente. Um espaço virtual se abre clamando por atualizar-se como obra, destituindo o agente e a condição dos papéis de protagonistas da existência. Ao longo do texto, a Água Viva de Clarice Lispector (1998) faz a articulação entre arte, filosofia e clínica na trama conceitual que construímos.
\end{abstract}

Palavras-chave: Diferença, Repetição, Virtual, Clínica.

\begin{abstract}
This article takes concepts developed for Gilles Deleuze (2006) in his work Difference and Repetition as material for the production of a critical perspective of the subjectivity, time and space's notions in the clinical field of Psychology. Such perspective calls for a cartography exercise in the clinical making and thinking, through a thought came off the representation categories, found in a immanence dimension. In this way, a virtual dimension asks for actualization as work, dismissing the agent and the condition of the main characters of the existence. Through the text, the Clarice Lispector's Água Viva makes the poetical-experimental resonance of the conceptual net that we construct.
\end{abstract}

Keywords: Difference, Repetition, Virtual, Clinic. 
Não quero ter a terrível limitação de quem vive apenas do que é passível de fazer sentido. Eu não: quero é uma verdade inventada. (LISPECTOR, 1998, p. 20).

\section{Repetição e Diferença}

Diferença e Repetição ${ }^{1}$, obra do filósofo francês Gilles Deleuze publicada em 1968, pode ser considerada a obra fundamental de sua trajetória, pois fornece uma consistente amostra de seu árduo trabalho em distinguir o pensamento filosófico do pensamento ortodoxo. Com Diferença e Repetição, Deleuze inaugura sua filosofia, caracterizando-se como um pensador da diferença, do sentido, do desejo e da multiplicidade, onde encontramos um pensamento pluralista, ontológico, ético e trágico (no sentido eminentemente nietzscheano). Para tanto, Diferença e Repetição é uma obra de crítica à representação e ao primado da identidade.

O próprio título da obra nos encaminha a esta crítica, pois ao primeiro contato, nos leva rapidamente a um senso-comum: diferença e repetição como um par antitético, uma o oposto da outra, um composto binário em que o sentido de uma se constrói pelo sentido contrário da outra. Mas Deleuze (2006a), num exercício complexo e difícil de condensar no conciso espaço deste artigo, torce e tenciona os conceitos de repetição e diferença, convidando-nos a adentrar num território movediço onde o senso comum e o bom senso desmoronam exatamente onde erguem suas ilusões de verdade.

É neste ponto que o pensamento ortodoxo aponta sua própria ruína. Para Deleuze (2006a, p. 316-319) o bom senso é uma verdade parcial (a razão) que se une ao sentimento do absoluto para caracterizar-se como essencialmente distribuidor e repartidor. Desta forma, é capaz de conjurar as diferenças numa regra de partilha universal que uniformiza o diverso e igualiza o desigual. 0 bom senso quer prever mais do que agir, moldando o sentido do tempo como uma flecha que vai de um passado representável a um futuro provável, do particular ao geral. É aí que se gesta o senso comum definido "subjetivamente pela suposta identidade de um Eu como unidade e fundamento de todas as faculdades e, objetivamente, pela identidade de um objeto qualquer ao qual se julga que todas as faculdades se reportem" num intermitente processo de recognição. Assim, o bom senso e o senso comum se refletem entre si constituindo as duas metades da ortodoxia: regra de partilha universal e regra universalmente partilhada, o que assegura as ilusões de uma verdade universal e eterna.

Somos envolvidos de tal forma por ilusões de universalidade, transcendência, eternidade e discursividade que acabamos por suportar o peso da circulação das opiniões dominantes que nos fazem prisioneiros de um horizonte relativo e imóvel, como se não 
pudéssemos suportar os movimentos e velocidades infinitas da imanência, de um horizonte absoluto (DELEUZE; GUATTARI, 1992, p. 67-68).

Foram essas ilusões que, ao longo da história da filosofia, submeteram a diferença às exigências da representação, onde um "elemento do saber se efetua através de um objeto pensado recognitivamente por um sujeito que pensa" (DELEUZE, 2006a, p. 272), o que fez com ela não pudesse ser pensada em si mesma, na relação do diferente com o diferente, mas apenas através das categorias representacionais enumeradas a seguir: 1) Identidade: fundada neste sujeito pensante que estende "ao conceito seus concomitantes subjetivos, a memória, a recognição e a consciência de si" - (categoria visível no cogito cartesiano: penso, logo, existo); 2) Semelhança: submete a diferença ao que reconhece como igual e remete o diverso ao estatuto de negativo; 3) Oposição: coloca o diverso de cabeça para baixo no intuito de produzir um contrário para afirmar o mesmo; 4) Analogia: determina os gêneros e as categorias que permitirão que a diferença seja julgada como o que é ou não é, fazendo da diferença uma simples diferença conceitual (Idem, p. 363374).

Neste cenário que nos dá a ilusão do estático, a repetição também acaba por subordinar-se às mesmas categorias, pois é "sempre representada como uma semelhança perfeita ou uma igualdade extrema", da ordem de uma generalidade e de uma materialidade mecânica. Assim, a repetição multiplica os exemplares sob um mesmo conceito, colocando este conceito fora de si para que cada apresentação nos pareça uma reapresentação. Torna-se, então, o próprio modelo da representação: compreensão através do mesmo e explicação através do negativo. (Idem, p.374-377)

Consequentemente, o pensamento também se encontra colado a uma imagem do que seja pensar, também subordinado às categorias da representação. Mas, ao longo da obra, o autor mostra que esta imagem do pensamento está muito longe do conforto que suas ilusões podem fazem crer em seu efeito estático.

A tarefa deleuzeana consistiu, nesta obra, em desatar os nós que subordinam a diferença, restaurando-a em três dimensões: no pensamento, livre da "identidade do conceito e do sujeito pensante"; na intensidade, liberando o diverso do semelhante; na Idéia, devolvendo a diferença ao problemático, retirando-a do jugo do negativo e da analogia do juízo. Por conseguinte, são a divergência e o descentramento que aparecem afirmados, por excelência, como o exercício da diferença.

O verdadeiro pensamento se pensa a si mesmo, essa espécie de pensamento atinge seu objetivo no próprio ato de pensar (LISPECTOR, 1998, p. 81). 
Já a repetição é liberada da obrigação generalista e assume seu estatuto de "singularidade não permutável e insubstituível" (DELEUZE, 2006a, p.19-20). O deslocamento e o disfarce são afirmados como o exercício da repetição, mas não com a função de esconder o mesmo, o verdadeiro. O deslocamento e o disfarce aparecem como os próprios elementos da repetição, o que permite que cada apresentação seja independente da outra. A repetição passa, então, a opor-se à representação ao mesmo tempo em que o movimento se opõe ao conceito e à representação do conceito (Idem, p. 29-32). Ao final, a diferença reencontra a repetição, pois só o que se repete é a diferença.

A repetição é pensada como um movimento puro, elementar, que não muda nada no objeto que se repete e sim, no espírito que a contempla passivamente (Idem, p. 98). É aí que o pensamento deleuzeano pode animar o pensamento da Psicologia na complexificação do conceito de subjetividade, pois para o autor, a subjetividade emerge de uma multiplicidade de hábitos contraídos passivamente na experimentação dessas repetições elementares, singulares e independentes (MACIEL JR; MELO, 2006, p. 70).

Neste percurso, encontramos o que aprisiona e liberta a diferença e a repetição e transpusemos este exercício para os processos de produção subjetivos e para o recorte clínico que nos cabe enquanto psicólogos, já que a Psicologia tradicional tem suas raízes filosóficas no que chamamos aqui de pensamento ortodoxo. Porém, a liberdade que podemos encontrar está longe de ser representável, quiçá nos devolverá algum conforto ou apaziguamento perdido. É a liberdade de habitar o que ainda não existe...

A harmonia secreta da desarmonia: quero não o que está feito, mas o que tortuosamente ainda se faz (LISPECTOR, 1998, p. 12).

\section{Tempo e Subjetividade}

Dentro de um pensamento aprisionado pelo efeito estático das categorias representacionais, o tempo tem três dimensões. Uma segue a outra numa série linear: passado-presente-futuro, onde cada termo da série é conseqüência do anterior. Para Deleuze (2006a, p.136-137), no entanto, esta é a imagem de um tempo simples demais. O que ele nos mostra é um conjunto complexo do tempo, operando por sínteses de um fundo indiferenciado, que não se relacionam entre si por derivação.

Se algo muda no espírito que contempla passivamente uma repetição elementar, não há uma repetição e um espírito preexistentes. Eles passam a existir quando entram em relação, onde uma síntese é capaz de se produzir (MACIEL JR; MELO, 2006, p. 70). 
Por isso, a primeira síntese que Deleuze (2006a) nos apresenta é aquela capaz de produzir um Eu, um Eu larvar, um espírito contemplativo que contrai aquilo de que procede, muito antes da possibilidade da sensação e muito aquém da representação. É uma contemplação, antes de tudo, orgânica: "Somos terra, água e ar contraídos, não só antes de reconhecê-los ou representá-los, mas antes de senti-los" (Idem, p.115). Por isso o Eu é um hábito, um hábito contraído passivamente na síntese que origina o tempo: um presente vivo e vivido, a contemplação do mundo e seus elementos em instantes independentes. Concebem-se, então, dois presentes, 0 empírico e atual que constitui a subjetividade, mas também um virtual $^{2}$ onde ela se gesta (PELBART, 1998, p.123-129).

É interessante notar como esta concepção de hábito é muito diferente das concepções tradicionais da Psicologia que o concebem como modo de ser, agir e pensar de um determinado sujeito que, por sua vez, o adquire pela repetição mecânica de ações por ele sofridas ou atuadas. A isto, Deleuze chamaria de sínteses ativas, meros efeitos da intenção de um indivíduo. No pensamento deleuzeano, no entanto, o hábito não explica o entendimento, nem é explicado por ele, quiçá por uma memória. O hábito explica a própria formação do ser na contemplação passiva de um presente vivo (MACIEL JR; MELO, 2006, p. 73-77).

Uma segunda síntese, também passiva, apresentada em Diferença e Repetição, é a da memória. Não a memória de um antigo presente, mas uma memória sub-representativa, de um passado transcendental ${ }^{3}$ que jamais foi presente. $O$ que se opõe a uma memória voluntária, uma síntese ativa, representativa, que vence o esquecimento empiricamente. $E$ é nesse passado imemorial que Deleuze localiza o objeto virtual como alvo erótico: perdido porque nômade, não-representável porque nunca vivido empiricamente. Portanto, temos também dois passados, um puro e imemorial e um passado vivido como um antigo presente, fundador da memória individual.

\footnotetext{
Eu, exposta às intempéries, eu, inscrição aberta no dorso de uma pedra, dentro dos largos espaços cronológicos legados pelo homem da pré-história. Sopra o vento quente das grandes extensões milenares e cresta a minha superfície. (LISPECTOR, 1998, p. 12).

Tenho o misticismo das trevas de um passado remoto. Cercam-me criaturas elementares, anões, gnomos, duendes e gênios (Idem, p.35).
}

Assim, "a subjetividade é o tempo", não se localiza nele, nem o experimenta. "Somos interiores a uma duração ontológica que desdobramos", da qual somos uma cisão, uma cisão que se 
desprende de um emaranhado virtual a cada instante (PELBART, 1998, p. 51-52).

A subjetividade, então, não provém do passado enquanto presente vivido e não é costurada por esta linha simplificada do tempo que nos reproduziria como uma série causal e identitária. A subjetividade é um eterno processo de distinção (Idem, p.52): distinguir-se de um todo virtual, distinguir-se do mundo, distinguir-se de si.

Esta distinção tem um operador: o acontecimento (DELEUZE, 2006, p.137). É ele quem produz "um intervalo entre a percepção e a ação, um interstício onde se aloja uma afecção" (PELBART, 1998. p.52) e abre uma fissura por onde pode vazar o virtual em busca de atualização. Por isso o Eu é sempre rachado por essa forma pura e vazia do tempo (DELEUZE, 2006a. p.133) e não habita outro lugar senão uma fissura.

E para que tenhamos um acontecimento precisamos estar diante do involuntário, do acaso, o que localizaria o acontecimento num evento imprevisível. Mas, ao mesmo tempo, o acontecimento se distingue do acidente. $O$ que é próprio do acontecimento não é a sua efetuação, mas a suspensão na decomposição do instante numa multiplicidade em devir. O acontecimento é a pura reserva do que ainda não é (Pelbart, 1998. p. 95-96).

Tenho um pouco de medo: medo ainda de me entregar pois o próximo instante é o desconhecido. O próximo instante é feito por mim? Ou se faz sozinho? Fazemo-lo juntos com a respiração (LISPECTOR, 1998, p. 1).

O extremo do tempo é aberto por esta fissura acontecimental e aí se gesta a terceira síntese do tempo, proposta em Diferença e Repetição. Ela descobre o futuro, mas não um futuro que sucede o presente como presente seguinte (DELEUZE, 2006a, p.137). Na fissura aberta pelo acontecimento, é a ação e a obra que interessam! O Eu é fragmentado, pois a ação se volta contra o agente. Ela não quer o Eu como condição, quer atingir o incondicionado, o virtual, aquilo que ainda não é. Esfacela-se o Eu, pois o que se vê no espelho é o desigual em si.

Não, isto tudo não acontece em fatos reais, mas no domínio de - de uma arte? Sim, de um artifício por meio do qual surge uma realidade delicadíssima que passa a existir em mim: a transfiguração me aconteceu (LISPECTOR, 1998, p. 19).

O tempo saiu dos eixos ${ }^{4}$ (DELEUZE, 1997, p. 36). E penetramos num passado de que não nos lembramos, povoado de pura virtualidade, de seres inexplicáveis pelo presente, de fantasmas vindos do futuro. 
A repetição do futuro é, por fim, a repetição por excelência. Todas as outras se subordinam a ela, pois em seu programa ela quer servir-se da repetição do hábito e da memória, mas apenas como estágios, pois o que ela quer mesmo é expulsar o agente e a condição em nome da obra e do produto; fazer com que, "para si-mesma, a repetição seja a diferença em si-mesma". (DELEUZE, 2006a, p.142).

O futuro é pra frente, pra trás e para os lados. O futuro é o que sempre existiu e sempre existirá (LISPECTOR, 1998, p. 34).

Encontramo-nos, então, em terras movediças, que pedem pela invenção de outros modos de andar, de olhar, de sentir, pois neste ponto, o solo em que nos enraizávamos e as alturas em que nos espelhávamos perderam sua solidez ${ }^{5}$. Ocupamos agora quatro dimensões.

\section{A clínica do virtual}

Preste atenção e é um favor: estou convidando você a mudar-se para um reino novo (LISPECTOR, 1998, p. 52).

No plano da subjetividade e do fazer clínico que se volta ao território existencial subjetivo, o pensamento deleuzeano que acima esboçamos, nos dá pistas de como operar uma clínica que se entende arrastada pelo plano virtual. Nesta perspectiva, não anunciamos novas técnicas psicoterápicas e sim, elementos de uma imagem do pensamento que está na base de um paradigma ético-estéticopolítico que deve se colocar como horizonte de qualquer prática.

Portanto, quando falamos de clínica, falamos de territórios capazes de produzir efeitos clínico-terapêuticos mesmo que deslocados de uma proposta clínica declarada. Incluem-se aí práticas religiosas, artísticas, esportivas, laborais, de recreação, de aprendizagem, enfim, uma lista interminável que pode se estender a qualquer pragmática existencial. E falamos aqui, mais especificamente, do domínio da psicologia enquanto disciplina acadêmica, onde a clínica é um território delimitado pelas práticas que tratam da saúde mental. Suas bases epistemológicas são diversas e seus campos de atuação se multiplicaram ao longo do tempo, mas aqui ficamos com aquilo que fundamenta a atuação do psicólogo analítico: um profissional procurado para tratar de questões, crises, impasses, adoecimentos e outras problemáticas, num espaço que chamaremos de psicoterapia. Tentaremos então enxergar esta clínica sendo afetada e violentada pelo pensamento deleuzeano tal como o apresentamos acima.

Começamos pelo passado. 
Para Deleuze (2006a) o exercício reminiscente, tão caro às pragmáticas tradicionais da Psicologia de orientação analítica, não busca o passado empírico, como se pudesse reapresentá-lo e representá-lo ao modo de um flashback (PELBART, 1998. p. 15). Toda reminiscência é um passado que se apresenta em busca de um objeto virtual. Por isso os deslocamentos e os disfarces... Por que procuraríamos o que há atrás do disfarce e seguiríamos aquilo que permanentemente se desloca? Se a criação está justamente no disfarce que se apresenta e no movimento que se faz?

"Desmascarar alguma coisa ou alguém é uma ilusão" (DELEUZE, 2006a. p.157). Atrás de uma máscara há outra máscara que apresenta, comunica e movimenta um objeto virtual. Mas o que denominamos objeto virtual, já que ele não pode ser encontrado nem identificado?

O objeto virtual é um objeto parcial, mas sua parcialidade não provém de uma origem total (o suposto objeto real encontrado num antigo presente), muito menos ele é parcial porque lhe falta uma parte. Permanecer não-totalizável é a essência do objeto virtual, pois ele não faz parte de um antigo presente, arquivo de memóriaslembranças, e sim, de um passado puro. É em direção a este passado puro e imemorial que nos remetemos eroticamente, durante 0 exercício da reminiscência, a um passado que jamais foi presente. Por isso a crítica de Deleuze a um antigo presente que viria determinar sua própria repetição, na série linear do tempo. Ao procurar um mesmo suposto verdadeiro que se repetiria sob os disfarces, ignoramos a diferença, um objeto virtual que insiste em animar o real. (I dem, p.150-155)

Nesta perspectiva, conceitos como os de fixação, regressão, trauma e cena primária, parecem, então, inadequados, pois pressupõem um tempo originário e outro derivado: o presente atual esconderia o presente vivido, porém recalcado e esquecido, através de disfarces ludibriadores. Os disfarces teriam aí a função de repetir uma mesma lembrança ainda não representada, na tentativa de dar a ela sua definitiva representação (PELBART, 1998. p.128). Porém, não somos fixados a um estado ou momento, mas a um movimento puro da repetição que se distingue de qualquer regressão (DELEUZE, 2006a, p. 308-309).

Pois, se a verdadeira repetição é da diferença, o disfarçante é ao mesmo tempo o disfarçado e se desloca nomadicamente de uma máscara à outra. Ora, no momento em que concebemos a repetição distinguida da representação, o repetido não pode ser representado. Não repetimos porque recalcamos e esquecemos. Esquecemos e recalcamos porque repetimos, porque não viveremos nada de novo por meio do representável, de um objeto já totalizado a que o novo deve submeter-se (Idem, p.157). 
Mesmo para Freud a tomada de consciência de uma vivência recalcada era de pouca serventia. É a transferência que permite a descoberta de um "além" e faz de "todo o tratamento uma viagem ao fundo da repetição", um jogo seletivo das máscaras que se inventam em nós e através de nós (Idem, p.43): invenção do passado, dramatização, encenação que dá aos fantasmas do futuro sempre um novo palco para uma nova apresentação.

\begin{abstract}
Mas se eu esperar compreender para aceitar as coisas nunca o ato de entrega se fará. Tenho que dar o mergulho de uma só vez, mergulho que abrange a compreensão, mas sobretudo a incompreensão. E quem sou eu para ousar pensar? Devo é entregar-me. Como se faz? Sei porém que só andando é que se aprende a andar e - milagre - se anda.

Eu, que fabrico o futuro como uma aranha diligente. E o melhor de mim é quando nada sei e fabrico não sei o quê (LISPECTOR, 1998, p. 62).
\end{abstract}

Quanto ao presente, ele é só o que existe. O tempo só se constitui numa síntese originária que incide sobre a repetição dos instantes e não é feita pelo espírito, mas se faz no espírito que a contempla passivamente, precedendo as sínteses ativas da memória e da reflexão. O futuro e o passado são dimensões de cada um desses instantes e não um conjunto do tempo totalizável no sujeito (MACIEL JR; MELO, 2006, p. 74).

É do presente que procedemos enquanto virtual e é ao presente, enquanto atual, que nos direcionamos. É do presente que contraímos aquilo que contemplamos e contemplar é, antes de tudo, questionar o próprio presente. A repetição se inscreve na necessidade, mas não na necessidade marcada por uma falta que exige uma ação de satisfação. É a necessidade de um espírito ávido que repete a pergunta: "que diferença há?" para assim extrair o novo da repetição (DELEUZE, 2006a, p.121).

A necessidade, portanto, se inscreve na abertura de uma questão e é muito mal compreendida no nível das sínteses ativas que a tomam como uma estrutura negativa, relacionada à carência, à intencionalidade e à utilidade. Ela se inscreve muito melhor na emergência de um excesso do transbordar das repetições que o espírito passivamente contempla (MACIEL JR; MELO, 2006, p. 77).

Então, o que é mais essencial num programa clínico é tratar de problemas e de questões. Pois os problemas e as questões são potências vindas de um fundo virtual e que se deixam resolver apenas parcialmente, numa coordenada espaço-temporal tão momentânea quanto evanescente. São potências de absurdo e de enigma que não se reduzem nem ao questionador, nem ao questionado (DELEUZE, 2006a, p. 277). 
Neste sentido, a maquinaria da interpretação também nos parece inadequada quando oferta uma representação, localizada num antigo presente e vivida por um determinado sujeito, para aquilo que só surge para se atualizar como inédito, caracterizando assim sua função de futuro, a função do inconsciente. Pois a estrutura do inconsciente $^{6}$ é questionadora e problematizante e não conflitual, oposicional ou de contradição (estrutura que o compreende submisso às categorias da representação). O próprio inconsciente é o virtual em sua potência problemática expansível (Idem, p.165).

\begin{abstract}
Para me interpretar e formular-me preciso de novos sinais e articulações novas que se localizem aquém e além de minha história humana. Transfiguro a realidade e então outra realidade, sonhadora e sonâmbula, me cria. E eu inteira rolo e à medida que rolo no chão vou me acrescentando em folhas, eu, obra anônima de uma realidade anônima só justificável enquanto dura a minha vida. E depois? Depois tudo o que vivi será de um pobre supérfluo (LISPECTOR, 1998, p. 21).
\end{abstract}

O futuro é, portanto, o desdobramento e a explicação do múltiplo, do diferente, do fortuito por si mesmos. O futuro está no virtual e não no amanhã. Então é preciso que a clínica dê conta, sobretudo desta terceira síntese e ocupe-se mais da obra do que do agente como sua condição. O sujeito é uma interface entre o virtual e o atual e é nos processos de atualização que um sujeito pode experimentar a potência da criação como processo de distinção intermitente de um fundo indiferenciado, do mundo e, consequentemente, de si mesmo. É este o programa de uma clínica do virtual:

Trata-se de produzir, na obra, um movimento capaz de comover o espírito fora de toda representação; (...) inventar vibrações, rotações, giros, gravitações, danças ou saltos que atinjam diretamente o espírito (DELEUZE, 2006a. p 29).

Ainda tenho medo de me afastar da lógica porque caio no instintivo e no direto, e no futuro: a invenção do hoje é meu único meio de instaurar o futuro (LISPECTOR, 1998, p. 12).

\title{
A clínica como cartografia
}

Os corpos são capazes de se expandir no espaço em latitude, longitude e altitude, mas é o inconsciente que se expande numa quarta dimensão.

Escrever é minha quarta dimensão (LISPECTOR, 1998, p. 4).

Enquanto clínica, uma quarta dimensão só pode ser a dimensão do virtual acessada por uma experimentação. Primeiramente, um programa clínico partiria da elaboração de mapas que contenham 
elementos bloqueadores da potência experimental, questionadora e problematizante e elementos passíveis de permitir a permeabilidade da interface virtual-atual localizada no sujeito. Assim, constrói-se um trabalho cartográfico que superpõe os mapas como um plano de imanência. Neste plano, eles podem se acoplar, se agenciar, se repelir e se compor de múltiplas, diferentes e inusitadas formas, pois experimentar é produzir atos cujo efeito se desconhece. A função da psicoterapia é acompanhar os deslocamentos e os disfarces que ali se inventam, atualizando uma potência virtual que pode flexibilizar impasses, crises e adoecimentos, mas, principalmente, multiplicar os problemas e as questões (ADAIME, 2008. p. 29). "A que estaríamos destinados senão a problemas que exigem até mesmo a transformação de nosso corpo e de nossa língua?" (DELEUZE, 2006a. p.272). O movimento clínico torna-se essencialmente cartográfico e a experimentação, uma pura "potência do falso", em direção ao futuro. Assim como o hábito, que se faz em nós e não é feito por nós, a experimentação a que nos referimos precisa ser distinguida de uma dimensão que toma a experiência como a aquisição de um comportamento de adaptação a um meio dado. É uma experimentação que torna o corpo e a linguagem passagens de um virtual para um atual e, assim, permite que inventemos tanto 0 mundo quanto a nós mesmos. Portanto, a subjetividade é um processo de invenção, a "diferença emergente" que transvaza através da repetição e não a conseqüência de um mundo concebido a priori (MACIEL JR; MELO, 2006, p. 79).

Por isso Clarice Lispector chama sua escrita de quarta dimensão. E todos nós temos um ponto onde a fissura dessa dimensão pode ser mais aberta, a interface mais permeável. Resta a um programa clínico procurar os melhores dispositivos para fazer, do que dali vaza e verte, obra de arte e, ao mesmo tempo, obra da vida. E se queremos dispositivos que movimentem uma potência do falso é preciso ir além da fala e da compreensão recognitiva... É preciso que se chegue à escrita, não necessariamente a escrita lingüística que agencia palavras, mas qualquer dispositivo capaz de permitir que o virtual se inscreva no atual tornando o agente, o coadjuvante, e a obra, o protagonista.

Eu me ultrapasso abdicando de meu nome, então sou o mundo. Sigo o mundo com voz única (LISPECTOR, 1998, p. 76).

É preciso lembrar que, se a aquisição de um hábito se faz por contemplação, ela precede a emergência de um sujeito. É aí que Deleuze pensa a estética como ética da existência, pois o domínio da subjetividade não pode mais ser separado do domínio da arte, como se a segunda fosse uma reflexão da primeira, tal como concebe o 
pensamento ortodoxo. É esta contemplação que permite nosso agenciamento com o virtual, que permite que se produza algo desse agenciamento e coloca nosso próprio ser em devir, fazendo com que nos diferenciemos de nós mesmos. Nessa contemplação originária e, portanto, estética, a subjetividade emerge de um composto de blocos de sensações heterogêneas (MACIEL JR; MELO, 2006, p. 80).

O que chamamos de blocos de sensações são compostos de afectos e perceptos. Afectos que não são confundidos com sentimentos ou afecções, eles transbordam a força daqueles que são atravessados por eles, excedem o vivido, e só se fazem conservar enquanto obra, enquanto bloco atualizado de perceptos que, assim como os afectos, ultrapassam a percepção (DELEUZE; GUATTARI, 1992, p. 213-214). Este conceito nos serve quando coloca em cheque os modelos da subjetividade tomada enquanto recognição de um mundo objetivado por um sujeito que pensa e sente este mundo. É um bloco de sensações que preenche o plano de composição no momento de uma síntese, preenchendo a si mesmo com aquilo que o contempla (Idem, p. 272).

Porém, nada disso se coloca na tentativa de subestimar o universo representacional, pois nós também o habitamos. Ele nos interessa especialmente como modo de funcionamento e reprodução de padronizações existenciais. Não podemos ignorar rotinas repetitivas de trabalho, relações afetivas modelizadas, modos de produção de subjetividade capitalísticos e serializados... Podemos conceber esses e outros sintomas, dentro da perspectiva aqui proposta, como existências que impermeabilizam a fissura do virtual: são fadigas em fazer novas distinções do que se contempla, fadigas de questionar...

Todos estes sintomas podem ser encarados como um aprisionamento do virtual por um cotidiano de mortificação e a psicoterapia, neste sentido, pode ser procurada como uma possibilidade de crítica. Compreender como esses sistemas funcionam e como afetam indivíduos e coletivos sociais faz parte de um programa que se oriente para uma criação prudente de aberturas (ADAIME, 2008, p.19).

O que é identitário e classificável pode sofrer um processo de deslizamento, de desvio, de permeabilização, e livrar-se da homogeneidade linear de uma cadeia causal, liberando heterogeneidades impessoais e pré-individuais a se agenciarem de múltiplas formas.

Assim, os modos de existência são pensados independentemente dos valores transcendentes (conforme nota 3) e das categorias representacionais que os colocam sob comparação, avaliação e seleção para decidir quais são os melhores e os piores através dos critérios do bom senso e do senso comum. Os critérios escolhidos são pensados pelo teor da existência, através dos movimentos traçados e 
das intensidades criadas sobre um plano de imanência: pura intensificação da vida (DELEUZE; GUATTARI, 1992, p. 98).

Um modo de existência criador é o único capaz de problematizar a si próprio e viver a existência como problema e o pensamento como intensidade. A superioridade intensiva é a dos afectos, o encontro com o heterogêneo onde toda a afectividade se abala e se redistribui sob um critério imanente onde a autoafirmação de nossas faculdades coincide com a afirmação do novo, do desvio, da saída (ZOURABICHVILI, 2004, p. 60-61).

Ocorreu-me de repente que não preciso ter ordem para viver. Não há padrão a seguir e nem há o próprio padrão: nasço (LISPECTOR, 1998, p. 35).

Ao percorrer mapas conceituais, existenciais e artísticos para propor um programa clínico que se coloque em contato com o virtual, tentamos conceber uma clínica muito mais próxima de uma máquina produtiva movida a virtual, do que uma máquina interpretativa movida por representação.

Um caso, então, não é a história de um sujeito, que responde à pergunta "que é?". Esta é uma questão que prejulga a resposta, pois a circunscreve numa suposta essência identitária. Ao trabalharmos um caso, é preciso reaver seu movimento real, aquele que percorre uma multiplicidade, e descolá-lo de um movimento abstrato que percorre apenas as categorias representacionais (DELEUZE, 2006b, p.155). Remetendo $o$ caso à sua heterogênese singular, 0 pensamento e a escrita podem acessar o virtual e serem acessados por ele, produzindo um outro independente do Eu, operando em direção à terceira síntese do tempo.

É neste sentido que afirmamos a presença da Água Viva, de Clarice Lispector (1998) para além de uma mera ilustração poética dos conceitos apresentados. Deleuze (1997) reserva aos grandes escritores o status de grandes filósofos. São eles que acessam esta quarta dimensão, a dimensão da invenção, da criação, dimensão que atualiza um virtual, já que tanto a experiência da escrita quanto a da clínica são inseparáveis da experimentação de devires, ou seja, do que chamamos aqui, dimensão virtual. Pois devir não é atingir uma forma identitária ou representacional, mas encontrar uma zona de indeterminação que se conecte com o fundo indiferenciado de onde vaza o objeto virtual.

Então, não se escreve com as próprias memórias, as próprias neuroses, com as reminiscências do vivido e sim, com esse passado puro e imemorial que anima a escrita e a vida como obra e produção e assim, racham o Eu do autor e o destituem de sua história pessoal. É aí que moram as potências fabuladoras que tornam a literatura uma saúde: enunciação coletiva de um povo por vir, questão de 
crítica e clínica, onde uma se torna inseparável da outra (DELEUZE, 1997, p. 11-16). Longe das opiniões dominantes do senso comum, das memórias do vivido e dos saberes generalistas de tendências homogeneizantes, a arte, a filosofia e a clínica podem ser pensadas como modos de habitar o indeterminado, de atualizar o virtual (DELEUZE; GUATTARI, 1992, p. 259-79).

Por isso, preferimos descolar a prática clínica de sua raiz etimológica grega Klinikos, que tem o sentido de 'debruçar-se sobre o leito', para nos aliarmos ao conceito epicurista de clinamen ${ }^{7}$, que nos dá o sentido da produção de desvios. Buscamos a potencialidade das variações existenciais através de um plano que se constrói a partir de encontros e acontecimentos em incessante mutação. Como espaço de clinamen, um acontecimento que produz rupturas, catalisa fluxos e decompõe-se em diversos outros, carrega a potência de ser um analisador. Como forma de crítica e não de compreensão, o espaço do clinamen é aquele onde se produz um desvio, onde as linhas causais se esvanecem na própria ilusão de continuidade, fixidez, permanência. Linhas causais se mostram, agora, mais à serviço de um aprisionamento subjetivo do que de uma liberação criativa. Assim, os movimentos desse plano possibilitam uma cartografia da confluência e da dispersão dessas linhas (FARINA, 2009, p. 28-9)

Esta é a proposta de uma clínica crítica e política, que será desenvolvida mais tarde por Deleuze e Guattari (1976), na obra O Anti-Édipo, sob a denominação de Esquizoanálise. São os desvios, as linhas esquizo, de fuga, de ruptura, que produzirão o mundo através das maquinarias de um desejo produtivo. A clínica esquizoanalítica recoloca a produção do mundo e da vida como obra de arte em uma dimensão eminentemente social (DELEUZE; GUATTARI, 1976, p. 377).

A tarefa de uma esquizoanálise é, portanto, destrutiva das representações pretensamente universais que aprisionam a subjetividade numa história individual e pessoal, descolada das produções político-sociais. Assim, a arte, a filosofia e a clínica se encontram na tarefa de crítica ao presente e de produção da vida por vir.

E Sou assombrada pelos meus fantasmas, pelo que é mítico, fantástico, gigantesco: a vida é sobrenatural (LISPECTOR, 1998, p. 27).

E quando estranho a palavra aí é que ela alcança o sentido. E quando estranho a vida aí é que começa a vida (Idem, p. 76).

\section{Referências Bibliográficas}

ADAIME, R. D. Clínica experimental: Programas para máquinas desejantes. Dissertação (Mestrado em Psicologia Clínica). 2008. 114f. Orientador Luiz Orlandi. Núcleo de Estudos da Subjetividade. 
Pontifícia Universidade Católica de São Paulo, São Paulo. Disponível em: http://biblioteca.universia.net

DELEUZE, G. Diferença e repetição. Trad. Luiz B. L. Orlandi e Roberto Machado. São Paulo: Graal, 2006a.

. O Método de dramatização. Trad. Luiz B. L. Orlandi. In:

A ilha deserta. São Paulo: Iluminuras, 2006b. p. 129-153.

Lógica do sentido. Trad. Luiz Roberto Salinas Fortes. São Paulo: Perspectiva, 2003.

DELEUZE, G.; GUATTARI, F. O Anti-Édipo. Capitalismo e esquizofrenia. Trad. Georges Lamazière. Rio de Janeiro: Imago, 1976.

O que é a filosofia? Trad. Bento Prado Jr. e Alberto Alonso Muñoz. São Paulo: Editora 34, 1992.

FARINA, J. T. Desertação. Dissertação (Mestrado em Psicologia Social e Institucional). 2009. 92f. Orientadora Profa. Dra. Tania Mara Galli Fonseca. Programa de Pós-Graduação em Psicologia Social e Institucional. Universidade Federal do Rio Grande do Sul. Disponível em: http: //www. lume. ufrgs.br/bitstream/handle/10183/17230/00071

1565. pdf?sequence $=1$

LISPECTOR, C. Água viva. Rio de Janeiro: Rocco, 1998.

MACIEL JR., A.; MELO, D. A. S. A Fundação do Subjetivo: O Hábito para Além da Psicologia. Revista do Departamento de Psicologia da Universidade Federal Fluminense, v. 18, n. 2, p. 69-82, Jul/Dez. 2006.

NIETZSCHE, F. Genealogia da moral. Uma polêmica. Trad. Paulo César de Souza. São Paulo: Companhia da Letras. 1998.

PASSOS, E.; BARROS, R. B. de. A construção do plano da clínica e o conceito de transdisciplinaridade. Psicologia: Teoria e Pesquisa, Brasília, Jan./Abr, 2000. v. 16, n.1, p. 71-79.

PELBART, P. P. O tempo não-reconciliado. São Paulo: Perspectiva: FAPESP, 1998.

ZOURABICHVILI, F. O vocabulário de Deleuze. Trad. André Telles. Rio de Janeiro, 2004.2 Disponível em: <http://www.dossie_deleuze.blogger.com.br>. Acesso em: 15 de agosto de 2008.

\section{Endereço para correspondência}

Juliane Tagliari Farina

Programa de Pós-Graduação em Psicologia Social e Institucional da Universidade Federal do Rio Grande do Sul, Rua Ramiro Barcelos, 2600, Sala 13, Térreo, CEP 90035-003, Porto Alegre - RS, Brasil

Endereço eletrônico: julianetfarina@hotmail.com

Tânia Mara Galli Fonseca

Programa de Pós-Graduação em Psicologia Social e Institucional da Universidade Federal do Rio Grande do Sul, Rua Ramiro Barcelos, 2600, Sala 13, Térreo, CEP 90035-003, Porto Alegre - RS, Brasil

Endereço eletrônico: tfonseca@via-rs.net 
Recebido em: 16/10/2008

Aceito para publicação em: 01/03/2010

Acompanhamento do processo editorial: Eleonôra Torres Prestrelo

\section{Notas}

* Psicóloga

** Psicóloga

${ }^{1}$ Diferença e Repetição é a publicação resultante da tese de doutorado de Gilles Deleuze orientada por Maurice de Gandillac.

${ }^{2}$ Em Deleuze, o virtual não se opõe ao real, apenas ao atual. O virtual significa que nem tudo é dado, nem passível de ser dado, mas que tudo que acontece provem do mundo enquanto imanência, onde o real se constitui de uma parte virtual e outra atual (ZOURABICHVILI, 2004, p. 62-63). Porém, o virtual não pode ser confundido com o possível. Este se opõe ao real e depende das características do já existente (e, portanto, representado) que Ihe conferem possibilidade. Já a atualização do virtual "sempre se faz por diferença, divergência ou diferençação. A atualização rompe tanto com a semelhança como processo quanto como com a identidade como princípio" (DELEUZE, 2006, p. 316-319).

${ }^{3}$ Para Deleuze, transcendental não se confunde com o transcendente que coloca os objetos fora e acima do mundo. Ao contrário, é aquilo que faz nascer o mundo, mas que não pode ser captado pelo senso comum. É um empirismo superior, impessoal, constituído de singularidades pré-individuais, nunca genéricas ou antecipáveis (ZOURABICHVILI, 2004, p. 27-28).

${ }^{4}$ Referência deleuzeana à expressão do Hamlet de Shakespeare the time is out of joint.

${ }^{5} \mathrm{O}$ que chamamos aqui de pensamento ortodoxo tem sua origem no pensamento platônico que funda o ser humano como sujeito da moral e da consciência e torna o conceito de sujeito um ideal tomado como universal e incontestável, uma individualidade dotada de um mundo interno profundo e inatingível ou pretensamente atingível pela análise de um psicólogo. É Platão quem inventa a transcendência (as alturas platônicas) opondo à vida imanente uma pretensão ideal, submetendo a vida a uma verdade divina, a uma seleção conforme o juízo de Deus (NIETZSCHE, 1998, p. 140). As ideias ganham status de anterioridade em relação à encarnação. As almas encarnadas, por sua vez, devem ser pretendentes a cópias o mais fiel possível da essência divina, garantindo seu valor de semelhança. Ancorado nas essências ideais, o platonismo funda o domínio da filosofia como domínio da representação preenchido pelas cópias-ícones, pelo fundamento enquanto modelo do Mesmo, do semelhante, da identidade (DELEUZE, 2003, p. 260-262).

6 Em 1972 Deleuze publica com Felix Guattari O Anti-Édipo, obra em que desenvolvem o conceito de inconsciente maquínico, cuja estrutura é vista como uma usina essencialmente produtiva, deslocando-o da estrutura representacional psicanalítica.

${ }^{7}$ Este conceito designa o desvio que permite que os átomos, ao caírem no vazio em virtude de seu peso e de sua velocidade, se choquem e se articulem na composição das coisas. A cosmogonia epicurista atribui a esses pequenos movimentos de desvio a potência de geração do mundo. É na afirmação desse desvio, do clinamen, portanto, que a clínica se faz (PASSOS; BARROS, 2000). 